\title{
Involvement of cyclin-dependent kinase-5 in the kainic acid-mediated degeneration of glutamatergic synapses in the rat hippocampus
}

\author{
Noora Putkonen, ${ }^{1,2}$ Jyrki P. Kukkonen, ${ }^{2,3}$ Guiseppa Mudo, ${ }^{4}$ Jaana Putula, ${ }^{3}$ Natale Belluardo, ${ }^{4}$ Dan Lindholm ${ }^{1,2}$ \\ and Laura Korhonen ${ }^{1,2,5}$ \\ ${ }^{1}$ Institute of Biomedicine/Biochemistry and Developmental Biology, University of Helsinki, Haartmaninkatu 8, FIN-00290 Helsinki, \\ Finland \\ ${ }^{2}$ Minerva Medical Research Institute, Biomedicum-2 Helsinki, Helsinki, Finland \\ ${ }^{3}$ Unit of Biochemistry and Cell Biology, Department of Veterinary Biosciences, University of Helsinki, Helsinki, Finland \\ ${ }^{4}$ Division of Human Physiology, Department of Experimental Biomedicine and Clinical Neuroscience, University of Palermo, \\ Palermo, Italy \\ ${ }^{5}$ Division of Child Psychiatry, Helsinki University Central Hospital, Helsinki, Finland
}

Keywords: calcium, cyclin-dependent kinase-5, hippocampus, kainic acid, synaptic degeneration

\begin{abstract}
Increased levels of glutamate causing excitotoxic damage accompany neurological disorders such as ischemia/stroke, epilepsy and some neurodegenerative diseases. Cyclin-dependent kinase-5 (Cdk5) is important for synaptic plasticity and is deregulated in neurodegenerative diseases. However, the mechanisms by which kainic acid (KA)-induced excitotoxic damage involves Cdk5 in neuronal injury are not fully understood. In this work, we have thus studied involvement of Cdk5 in the KA-mediated degeneration of glutamatergic synapses in the rat hippocampus. KA induced degeneration of mossy fiber synapses and decreased glutamate receptor (GluR)6/7 and post-synaptic density protein 95 (PSD95) levels in rat hippocampus in vivo after intraventricular injection of $\mathrm{KA}$. KA also increased the cleavage of Cdk5 regulatory protein p35, and Cdk5 phosphorylation in the hippocampus at $12 \mathrm{~h}$ after treatment. Studies with hippocampal neurons in vitro showed a rapid decline in GluR6/7 and PSD95 levels after KA treatment with the breakdown of p35 protein and phosphorylation of Cdk5. These changes depended on an increase in calcium as shown by the chelators 1,2-bis(o-aminophenoxy)ethane- $N, N, N^{\prime}, N^{\prime}$-tetraacetic acid acetoxymethyl ester (BAPTA-AM) and glycol-bis (2-aminoethylether)- $N, N, N^{\prime}, N^{\prime}$-tetra-acetic acid. Inhibition of Cdk5 using roscovitine or employing dominant-negative Cdk5 and Cdk5 silencing RNA constructs counteracted the decreases in GluR6/7 and PSD95 levels induced by KA in hippocampal neurons. The dominantnegative Cdk5 was also able to decrease neuronal degeneration induced by KA in cultured neurons. The results show that Cdk5 is essentially involved in the KA-mediated alterations in synaptic proteins and in cell degeneration in hippocampal neurons after an excitotoxic injury. Inhibition of pathways activated by Cdk5 may be beneficial for treatment of synaptic degeneration and excitotoxicity observed in various brain diseases.
\end{abstract}

\section{Introduction}

Excitotoxicity with overactivation of ionotropic glutamate receptors (GluRs) is a major cause of cell death in several neurological diseases. Excitotoxicity is accompanied by an increase in calcium levels in neurons with activation of various proteases, such as calpains (Vanderklish \& Bahr, 2000) and caspases (Mattson, 2003). However, the precise signaling pathways for cell demise in excitotoxicity are not fully understood. We have previously shown that excitotoxicity induced by the GluR agonist kainic acid (KA) leads to endoplasmic reticulum stress in hippocampal neurons with subsequent cell degeneration (Sokka et al., 2007). Concomitant with changes in

Correspondence: L. Korhonen, ${ }^{1}$ Institute of Biomedicine/Biochemistry, as above. E-mail: laura.t.korhonen@helsinki.fi

Received 19 January 2011, revised 23 July 2011, accepted 28 July 2011 signaling pathways, synaptic proteins are affected in many neurological disorders (Korhonen \& Lindholm, 2004; Korhonen et al., 2005). In this work, we have studied the role of cyclin-dependent kinase-5 (Cdk5) in the alterations of synaptic proteins by KA as a means of understanding early signals mediating excitotoxicity in hippocampal neurons.

The proline-directed serine/threonine protein kinase Cdk5 is an atypical cyclin-dependent kinase expressed primarily in post-mitotic neurons and activated by binding to the $\mathrm{p} 35$ and p39 activator proteins (Tsai et al., 1994; Cai et al., 1997). Deregulation of Cdk5 secondary to cleavage of p35 and p39 proteins occurs in some neurodegenerative diseases (Weishaupt et al., 2003), such as Alzheimer's disease (Kobayashi et al., 1993; Noble et al., 2003) and Huntington's disease (Paoletti et al., 2008). Lewy bodies, accumulating in Parkinson's disease, are also immunoreactive for Cdk5 and p35 proteins (Nakamura et al., 1997). 
It has been shown that $\mathrm{Cdk} 5$ is important for synaptic plasticity and learning, and for normal development of the brain (Ohshima et al., 1996; Chae et al., 1997; Zhang et al., 1997; Hawasli \& Bibb, 2007; Lai \& Ip, 2009). Cdk5 influences the clustering of the postsynaptic density protein 95 (PSD95) complex (Morabito et al., 2004) and regulates trafficking of metabotropic GluRs (Orlando et al., 2009) and $N$-methyl-D-aspartate (NMDA) receptor subunits (Li et al., 2001). These observations suggest that Cdk5 is important for the regulation of GluRs and proper synaptic function in the brain.

Kainate receptors (KARs) are involved in both pre- and postsynaptic functions in the nervous system, and are important in synaptic plasticity and learning (Jane et al., 2009; Vincent \& Mulle, 2009). KARs are homo- or heteromeric combinations of five types of subunits, GluR5 [glutamate receptor ionotropic kainate (GIRK)1] GluR6 (GRIK2), GluR7 (GRIK3), KA1 (GRIK4) and KA2 (GRIK5) (Jaskolski et al., 2005). As shown using gene-deleted animals, GluR6 is essentially involved in KA-induced epileptic seizures and in neuronal degeneration in the cornu ammonis (CA)3 region in the hippocampus (Mulle et al., 1998). In this work, we found that KA induces an activation of Cdk5 in cultured hippocampal neurons as well as in the hippocampus in vivo. KA treatment decreased the levels of GluR6/7 and PSD95 in the hippocampal neurons. Inhibition of Cdk5 using roscovitine, or the use of silencing RNA (siRNA) or dominantnegative (DN) Cdk5 constructs counteracted the decreases in these proteins in cultured hippocampal neurons, indicating an important role of Cdk5 in KA-mediated synaptic degeneration and excitotoxicity.

\section{Materials and methods}

\section{Animals}

Experiments were approved by the ethical committees at the University of Helsinki and the University of Palermo, and carried out in accordance with the European Communities Council Directive (86/609/EEC). Adult male Wistar rats (200-300 g) (B\&K, Hull, UK) were injected with KA (Sigma, Helsinki, Finland) into the lateral ventricle $(0.35 \mu \mathrm{g} / \mu \mathrm{L})$ in a volume of $0.5 \mu \mathrm{L}$ per side as described previously (Sokka et al., 2007), and killed at different time-points from $15 \mathrm{~min}$ to $48 \mathrm{~h}$. Controls received an equal volume of saline. Rats were decapitated under deep anesthesia with chloral hydrate, and brains were dissected, frozen in isopentane, cooled in liquid nitrogen and stored at $-70{ }^{\circ} \mathrm{C}$ until analysis. The right side of the brain was used for histology and the left for western blot analyses.

\section{Neuronal cultures}

Hippocampal neurons were prepared from embryonic day 17 Wistar rats (Harlan, Holland) and plated on poly-ornithine (Sigma)-coated six-well plates at a density of $2 \times 10^{6}$ cells $\left(2.0 \mathrm{~cm}^{2}\right)$. Cells were cultured in Neurobasal medium containing 2\% B27 as described previously (Korhonen et al., 2001; Sokka et al., 2007; Kairisalo et al., 2009). Cell death was induced by treating neurons for different times with $100 \mu \mathrm{M} \mathrm{KA}$ (Calbiochem, Espoo, Finland), which induces cell death in approximately 40-50\% of the neurons within $24 \mathrm{~h}$ as reported previously (Korhonen et al., 2001; Sokka et al., 2007). In some experiments, 1-10 $\mu \mathrm{M}$ 1,2-bis(o-aminophenoxy)ethane- $N, N, N^{\prime}, N^{\prime}$ tetra-acetic acid acetoxymethyl ester (BAPTA-AM) (Sigma), $20 \mu \mathrm{M}$ roscovitine (Sigma) or $2 \mathrm{mM}$ glycol-bis(2-aminoethylether)$N, N, N^{\prime}, N^{\prime}$-tetra-acetic acid (EGTA) was added 10-60 min before KA.

\section{Modulation of cyclin-dependent kinase-5 in neurons}

To downregulate Cdk5, $5 \times 10^{6}$ neurons were transfected with $100 \mathrm{~nm}$ siRNA constructs against Cdk5 (On TargetPlus Smartpool, Dharmacon) using the Rat Neuron Nucleofector system (Amaxa GmbH, Germany) essentially as described previously (Kairisalo et al., 2009). A scrambled siRNA construct was used as control. Cdk5 activity was also inhibited using the DN-Cdk5 expression plasmid with mutation in the active site (D144N) linked to the hemagglutinin epitope (van den Heuvel \& Harlow, 1993) or to enhanced green fluorescent protein (EGFP) (courtesy of Dr Tsai, Massachusetts Institute of Technology, USA). The DN-Cdk5-EGFP was transfected into hippocampal neurons as above, and the vector containing EGFP was used as control. After 5 days in culture, neurons were treated with $100 \mu \mathrm{M} \mathrm{KA}$ for $1-24 \mathrm{~h}$ and immunoblots were made as described below.

\section{Calcium imaging}

Hippocampal neurons plated on polyornithine-coated glass coverslips were loaded with $4 \mu \mathrm{M}$ fura-2 acetoxymethyl ester (Invitrogen, Carlsbad, CA, USA) for $20 \mathrm{~min}$ at $37{ }^{\circ} \mathrm{C}$ in Hepes-buffered medium $\left(137 \mathrm{~mm} \mathrm{NaCl}, 5 \mathrm{~mm} \mathrm{KCl}, 1 \mathrm{~mm} \mathrm{CaCl} 2,1.2 \mathrm{~mm} \mathrm{MgCl}_{2}, 0.44 \mathrm{~mm}\right.$ $\mathrm{KH}_{2} \mathrm{PO}_{4}, 4.2 \mathrm{~mm} \mathrm{NaHCO} 3,10 \mathrm{~mm}$ glucose, $20 \mathrm{~mm}$ Hepes, $\mathrm{pH}$ 7.4), rinsed once and used immediately. $\mathrm{Ca}^{2+}$ measurements were performed at $35{ }^{\circ} \mathrm{C}$ using a Nikon TE2000 fluorescence microscope [magnification 20× and numerical aperture $0.75(20 \times / 0.75)$ air objective] and Andor iXon 885 EM-CCD camera under the control of Nikon NIS ELEMENTS AR software with 6D extension essentially as described previously (Korhonen et al., 2005; Reijonen et al., 2010). For $\mathrm{Ca}^{2+}$ imaging, the cells were excited with alternating 340 and $380 \mathrm{~nm}$ light (Sutter DG4 Plus) and the emitted light collected through a $400 \mathrm{~nm}$ dichroic mirror and a $450 \mathrm{~nm}$ long-pass filter. Transfected cells were selected based upon EGFP fluorescence. Additions were made by constant perfusion (Hepes-buffered medium). Regions of interest (cell bodies) were defined in NIS software and the data extracted to Microsoft Excel for visualization and quantification. A total of 19-70 cells were measured in each experiment, and each experiment was repeated four times or more.

\section{Western blotting}

Immunoblotting was performed essentially as described previously (Korhonen et al., 2001; Sokka et al., 2007; Reijonen et al., 2008; Kairisalo et al., 2009). In brief, hippocampal tissue and neurons were lysed using ice-cold radioimmunoprecipitation assay buffer $(150 \mathrm{~mm}$ $\mathrm{NaCl}, 1 \%$ Triton-X-100, $0.5 \%$ sodium deoxycholate, $1 \%$ sodium dodecyl sulfate, $50 \mathrm{~mm}$ Tris-HCl, $\mathrm{pH}$ 7.4) supplemented with protease inhibitor cocktail (Roche, Espoo, Finland) and phosphatase inhibitors (PhoStop; Roche). Equal amounts of protein were subjected to sodium dodecyl sulfate-polyacrylamide gel electrophoresis and blotted onto nitrocellulose filters (Amersham, Helsinki, Finland), which were incubated for $1 \mathrm{~h}$ in 5\% skimmed milk or bovine serum albumin, in $50 \mathrm{~mm}$ Tris- $\mathrm{HCl}, \mathrm{pH} 7.5,150 \mathrm{~mm} \mathrm{NaCl}, 0.1 \%$ Tween-20 and then with primary antibodies overnight at $4{ }^{\circ} \mathrm{C}$. These included antibodies against GluR6/7 (diluted 1: 1000, no. 04-921; Millipore/Upstate), PSD95 (1 : 2000, no. 610496; BD Biosciences, VWR International Oy, Espoo, Finland), Cdk5 (1:2000, no. 05-364; Millipore/Upstate), [phospho-cyclin-dependent-kinase-5 (p-Cdk5)(tyrosine 15)](Y15) (1:1000, no. sc-12918; Santa Cruz Biotechnologies, AH Diagnostics, Helsinki, Finland), p35/25 (1 : 1000, no. C64B10, Cell Signaling Technologies, Finnzymes, Helsinki, Finland) and $\beta$-actin (1 : 1000, no. 2066; Sigma). After washing, the filter was incubated with horseradish 
peroxidase-conjugated secondary antibodies (1:2500; Jackson ImmunoResearch Laboratories, Espoo, Finland), followed by detection using enhanced chemiluminescence (Pierce, Helsinki, Finland). Quantifications were performed using the IMAGEJ software (version 1.41o).

\section{Immunochemistry}

In vivo

Rat brain sections $(10 \mu \mathrm{m})$ were fixed for $10 \mathrm{~min}$ at $-20{ }^{\circ} \mathrm{C}$ using acetone:methanol $(1: 1)$. Slides were incubated for $1 \mathrm{~h}$ with phosphate-buffered saline $/ 5 \%$ bovine serum albumin (Sigma) $/ 0.1 \%$ Triton-X-100 at room temperature $\left(20{ }^{\circ} \mathrm{C}\right)$, and then overnight at $4{ }^{\circ} \mathrm{C}$ with primary antibodies [PSD95 (1: 500; no. 12093; Abcam), GluR6/7 (1:100), neuronal nuclei (1:100; MAB377, Millipore/Chemicon) or $\beta$-tubulin (1:500; MMS4351, Nordic Biosite/Covance)] followed by secondary Alexa 488- or 594-conjugated antibodies (1:500; Jackson ImmunoResearch Laboratories). The nuclei were counterstained with bisbenzimide/Hoechst 33258 (Sigma).

\section{In vitro}

Neurons were fixed for 20 min using $4 \%$ paraformaldehyde, incubated for $1 \mathrm{~h}$ using phosphate-buffered saline/5\% bovine serum albu$\min / 0.1 \%$ Triton-X and stained as above with antibodies for GluR6/7, PSD95, p-Cdk5 and synapsin I (1 : 500, no. 61392; Nordic Biosite/Covance). Stainings were visualized by fluorescent microscope (Leica DM4500B, Espoo, Finland).

\section{Cell degeneration assay}

In vivo

Fluoro-Jade staining for degenerating nerve cells was performed essentially as described previously (Korhonen et al., 2001, 2005; Sokka et al., 2007).

\section{In vitro}

Hippocampal neurons were transfected with DN-Cdk5-EGFP or with EGFP expression vector as above. KA $(100 \mu \mathrm{M})$ was added for $24 \mathrm{~h}$ and the nuclei were labeled with Hoechst 33258 blue (Sigma). The number of cells with condensed or fragmented chromatin was counted as an index of degenerating neurons.

\section{Confocal imaging}

Neurons were analyzed at room temperature with a confocal microscope (LSM 510 Meta; Carl Zeiss, Inc.) using LSM AIM software and a magnification $63 \times$ and numerical aperture 1.4 $(63 \times / 1.4)$ Plan-Apochromat oil objective. Images were processed using IMAGEJ and ADOBE PHOTOSHOP CS software.

\section{Quantification and statistics}

Statistical comparisons were performed using one-way ANOVA followed by a Bonferroni or Tukey's (if more than five groups) post-hoc test. The Student's unpaired $t$-test was used in experiments with two groups. $P \leq 0.05$ was considered significant. Four to eight rats were used for each time point in vivo, and the in vitro assays were repeated more than three times. Values are expressed as mean \pm SEM

\section{Results}

Kainic acid induces synaptic degeneration and decreases post-synaptic density protein 95 and glutamate receptor 6/7 levels in rat hippocampal neurons in vivo

To study the hippocampal pathways altered in excitotoxicity, we treated rats with KA in vivo as described in Materials and methods. Intraventricular injections of KA have been shown to mainly cause cell degeneration of neurons in the CA3 region of the hippocampus as well as in the amygdala and less cell degeneration of CA1 neurons, which is observed more with intraperitoneal injections. To study neuronal degeneration, we used Fluoro-Jade, which has been shown to detect both degenerating cell bodies and dendrites after excitotoxicityinduced injuries in rat retina (Chidlow et al., 2009) and dopaminergic neurons (El-Khodor \& Burke, 2002). Fluoro-Jade D staining revealed a degeneration of neurites in the hippocampal CA3 area in the KAtreated rats (Fig. 1A) and a reduction in PSD95-positive synaptic terminals in the CA3 area in the hippocampus (Fig. 1B). Immunoblotting of tissue lysates showed a reduction in PSD95 levels in the hippocampus at 12-48 $\mathrm{h}$ after KA administration (Fig. 1C; one-way ANOVA with Bonferroni post-hoc test and Student's unpaired $t$-test, $P<0.01$ for control vs. $12 \mathrm{~h} \mathrm{KA}$ and $P<0.05$ for control vs. $48 \mathrm{~h}$ and $72 \mathrm{~h} \mathrm{KA}$ ).

We then studied the effect of KA on GluR6, which is a subtype of GluR in the brain that is important for KA-mediated effects (Mulle et al., 1998). For this we used an antibody that recognizes both GluR6 and GluR7 receptor subtypes, and therefore we here use the term GluR6/7. It is of note that the expression of GluR7 is very low in the hippocampus particularly in the CA3 area (Bureau et al., 1999), and thus our data may primarily reflect changes in GluR6. Immunostaining data showed that GluR6/7 decreased in the CA3 area of the hippocampus at 12-24 h after KA administration (Fig. 1D). Double staining using antibodies against neuronal nuclei, microtubuli ( $\beta$-tubulin) and GluR6/7 indicated that the decrease in GluR6/7 in the mossy fiber area after KA occurred with the preservation of the cell soma of many CA3 neurons (Fig. 1E). Immunoblotting of tissue lysates also showed a downregulation of GluR6/7 in the hippocampus at $3 \mathrm{~h}$ after KA administration with a rebound at longer times that may reflect new synthesis of the receptor during the recovery phase (Fig. 1F; one-way ANOVA with Bonferroni post-hoc test, $P<0.01$ for control vs. $6 \mathrm{~h} \mathrm{KA}$ and $P<0.05$ for control vs. 3, 12, 24 and $72 \mathrm{~h}$ $\mathrm{KA})$.

Kainic acid also decreases post-synaptic density protein 95 and glutamate receptor 6/7 levels in hippocampal neurons in vivo

The effects of KA in vivo are rather complex and reflect changes in individual neurons, as well as alterations in neuronal circuits and in activation of glial cells that occur with time. To obtain a more detailed and mechanistic insight into the KA-mediated effects, we studied cultured hippocampal neurons prepared from rat hippocampus. Data showed that KA also induced a decrease in PSD95 levels in cultured hippocampal neurons that occurred within the first hours of incubation, as shown by immunostaining and immunoblots (Fig. 2A and B; one-way ANOVA with Bonferroni post-hoc test, $P<0.01$ control vs. 1 and $3 \mathrm{~h} \mathrm{KA}$ ).

Immunostaining of GluR6/7 in the hippocampal neurons showed that the addition of KA also rapidly reduced GluR6/7, observed particularly within the dendrites of hippocampal neurons (Fig. 2C). Immunoblotting confirmed that the levels of GluR6/7 in the hippocampal neurons decreased markedly within the first $30 \mathrm{~min}$ 

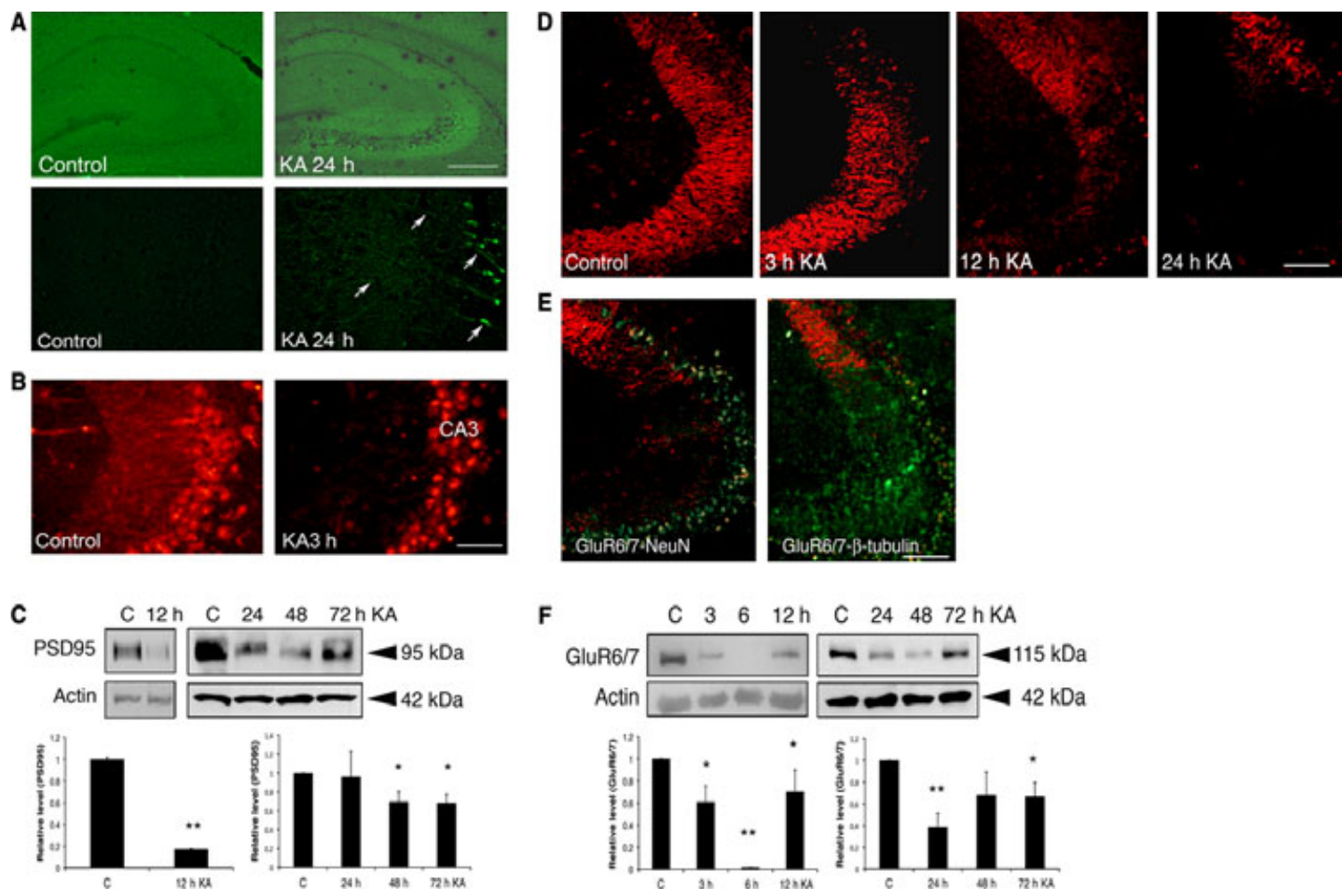

FIG. 1. KA treatment induces degeneration of hippocampal synapses and reduces levels of PSD95 and GluR6/7 in vivo. (A) Rats were treated with KA for 24 h as described in Materials and methods. Upper panel: whole hippocampus. Lower panel: higher magnification. Fluoro-Jade staining (green fluorescence) showed cell degeneration in the rat hippocampal CA3 area by KA. Arrows indicate some of the degenerating neurons. Scale bar: upper panel, $500 \mu \mathrm{m}$; lower panel, $100 \mu \mathrm{m}$. (B) Immunostaining was performed as described in Materials and methods. PSD95 immunoreactivity was reduced in the CA3 region. Scale bar, $100 \mu$ m. (C) Immunoblots were made as described in Materials and methods. PSD95 was downregulated after KA and $\beta$-actin was used as control (C). Values are means + SEM, $n=3$. ${ }^{*} * P<0.01$ or $* P<0.05$ for KA vs. C. (D) GluR6/7 immunoreactivity (red) in the CA3 area was reduced by KA treatment. Scale bar, $100 \mu$ m. (E) Immunostaining of GluR6/7 (red) in conjunction with the nuclear marker, neuronal nuclei (NeuN), or the microtubule marker, $\beta$-tubulin (green), at $12 \mathrm{~h}$ of KA treatment. Note reduction in GluR6/7 with the preservation of neuronal soma. Scale bar, $100 \mu$ m. (F) Immunoblot. Note a decrease in GluR6/7 after KA. $\beta$-actin was used as control (C). Values are means + SEM, $n=3$. $* * P<0.01$ or $* P<0.05$ for KA vs. C.

after KA addition (Fig. 2D and E; one-way ANOVA with Tukey's post-hoc test, $P<0.01$ for control vs. $30 \mathrm{~min}-24 \mathrm{~h} \mathrm{KA}$ ). This decrease in GluR6/7 by KA in vitro was more robust and long lasting than that observed in vivo (cf. Fig. 1F), suggesting that there is a more finetuned regulation of GluR6/7 levels in brain compared with the in vitro situation.

\section{Kainic acid induces a calcium- and calpain-dependent cleavage of 335 protein in cultured hippocampal neurons}

The activation of GluRs is linked to increases in intracellular calcium that in turn affect various signaling molecules in neurons. We have previously shown that KA induces endoplasmic reticulum stress and increases calcium levels in cultured hippocampal neurons (Sokka et al., 2007). In a search for changes in upstream molecules, we observed that treatment of cultured hippocampal neurons with $100 \mu \mathrm{M}$ KA caused a cleavage of the Cdk5 activator protein p35 into the p25 fragment that started at about 15 min after KA addition (Fig. 3A and B; one-way ANOVA with Bonferroni post-hoc test, $P<0.01$ control vs. 15 min-3 h KA). To study whether the breakdown of p35 by KA was linked to changes in calcium levels, we analyzed the dose- and timedependent calcium movements in KA-treated hippocampal neurons. Data showed that KA treatment resulted in a dose-dependent increase in intracellular calcium level (Fig. 3C) with the activation of the calcium-dependent protease calpain, shown by the accumulation of calpain-specific $145 \mathrm{kDa}$ cleavage products of $\alpha$-spectrin (Fig. 3D). Inhibition of the intracellular calcium increase by the chelation of intracellular or extracellular calcium using BAPTA-AM (Fig. 3E and F; one-way ANOVA with Bonferroni post-hoc test, $P<0.01$ for control vs. KA and $P<0.01$ for KA vs. KA+BAPTA-AM) or EGTA (Fig. 3G and $H$ ), respectively, attenuated the accumulation of $\mathrm{p} 25$ brought about by KA. In addition, the calpain inhibitor XI prevented the p35 cleavage by $\mathrm{KA}$, indicating that calpain is involved in this process (Fig. 3G and H; one-way ANOVA with Bonferroni post-hoc test, $P<0.01$ for control vs. KA and $P<0.01$ for KA vs. EGTA+KA and $P<0.01$ for KA vs. XI+KA).

Kainic acid induces an increase in cyclin-dependent kinase-5 phosphorylation in hippocampal neurons in culture and in vivo

Previous studies have shown that the cleavage of p35 into p25 results in the deregulation of $\mathrm{Cdk} 5$ with changes in the localization and stability of Cdk5 (Kusakawa et al., 2000; Lee et al., 2000; Asada et al., 2008). To study the role of Cdk5 in the excitotoxicity induced by KA, we analyzed p-Cdk5, as a measure of the increased activation of this kinase. Data showed that $100 \mu \mathrm{M}$ KA induced a timedependent increase in $\mathrm{Cdk} 5$ phosphorylation in the hippocampal neurons after $30 \mathrm{~min}$ of incubation (Fig. 4A and B; one-way ANOVA with Bonferroni post-hoc test, $P<0.01$ for KA vs. $1 \mathrm{~h}-\mathrm{KA}$ ). Immunostaining further revealed that an accumulation of phosphor- 

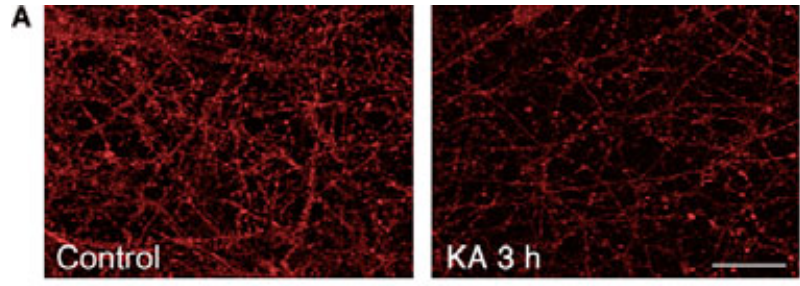

B
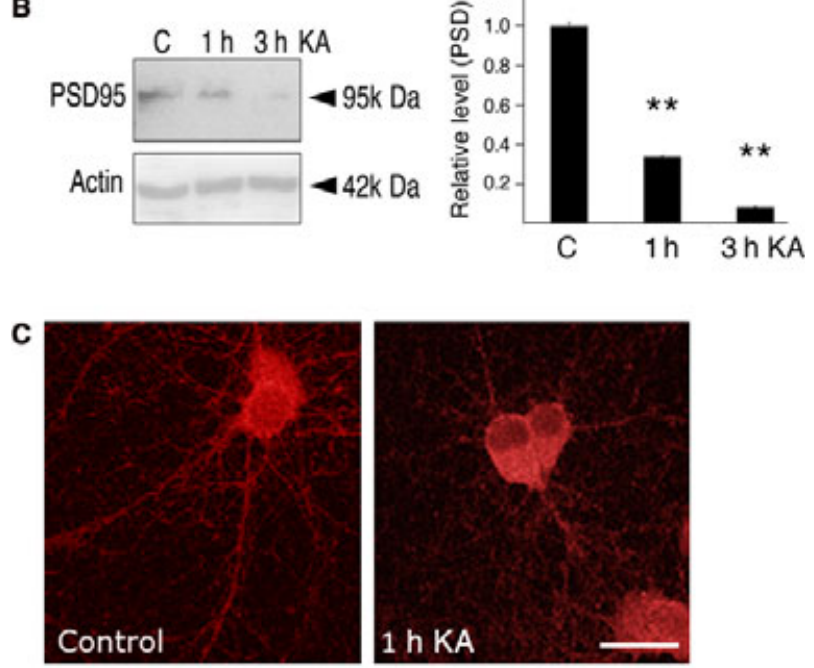

D C 5' $15^{\prime} 30^{\prime} 90^{\prime} 3 \mathrm{~h} 6 \mathrm{~h} 16 \mathrm{~h} 24 \mathrm{~h} \mathrm{KA}$

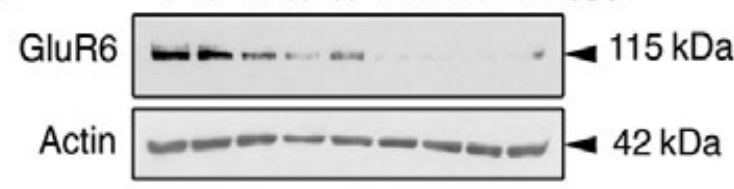

E

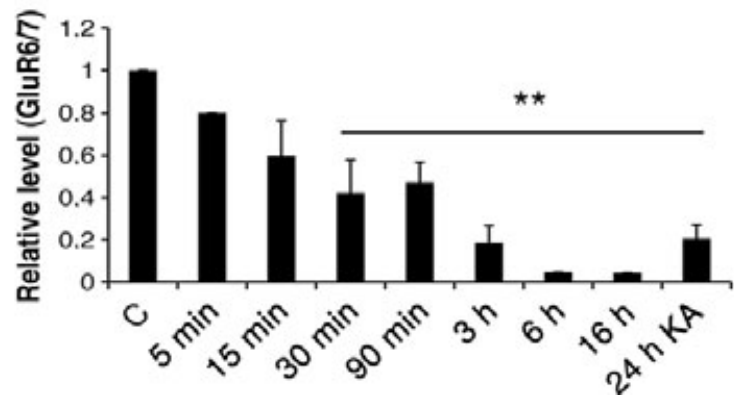

FIG. 2. KA downregulates PSD95 and GluR6/7 in cultured hippocampal neurons. Hippocampal neurons were cultured from embryonic day 17 rat hippocampus and treated with $100 \mu \mathrm{M} \mathrm{KA}$ and analyzed further as described in Materials and methods. (A) Immunostaining. PSD95 immunoreactivity was reduced in hippocampal neurons at $3 \mathrm{~h}$ after KA treatment. Scale bar, $5 \mu \mathrm{m}$. (B) Immunoblot shows downregulation of PSD95. Values are means + SEM, $n=3$. $* * P<0.01$ for KA vs. control (C). (C) Immunostaining. GluR6/7 was decreased within dendrites after KA stimulation. Scale bar, $20 \mu \mathrm{m}$. (D) Immunoblots. Neurons were incubated with KA for various periods of time. GluR6/7 decreased starting after $15 \mathrm{~min}$ of incubation. $\beta$-actin was used as control (C). (E) Values are means + SEM, $n=3$. $* * P<0.01$ for KA vs. C. PSD, postsynaptic density.

ylated Cdk5 protein occurred within neurites in KA-treated neurons (Fig. 4C). Pre-treatment of cells with BAPTA-AM or EGTA reduced the Cdk5 phosphorylation induced by KA (Fig. 4D and E; one-way ANOVA with Tukey's post-hoc test, $P<0.01$ for control vs. KA,
$P<0.01$ for KA vs. EGTA-KA and $P<0.01$ for KA vs. BAPTA$\mathrm{AM}+\mathrm{KA}$ ), showing an involvement of calcium in the regulation of Cdk5 by KA. Immunoblots using tissue lysates from KA-treated rats substantiated the data obtained in vitro, and showed an increase in $\mathrm{p}-\mathrm{Cdk} 5$ and in the breakdown of p35 by $\mathrm{KA}$ in the hippocampus occurring mainly at $12 \mathrm{~h}$ after KA administration (Fig. 4F and G; oneway ANOVA with Tukey's post-hoc test, $P<0.01$ for control vs. $12 \mathrm{~h}$ KA vs. control in the case of $\mathrm{p}-\mathrm{Cdk} 5$ and $\mathrm{p} 25$, and $P<0.05$ for control vs. 24-72 h KA in the case of p35).

\section{Inhibition of cyclin-dependent kinase- 5 counteracts the effects of kainic acid in cultured hippocampal neurons}

To study the role of Cdk5 in more detail we sought to inhibit its action in the hippocampal neurons. Pre-treatment of the neurons with roscovitine, a known inhibitor for various cyclin-dependent kinases including Cdk5 (Meijer et al., 1997), reduced the downregulation of GluR6/7 and PSD95 observed with KA at $3 \mathrm{~h}$ (Fig. 5A and B; oneway ANOVA with Tukey's post-hoc test, $P<0.01$ for $3 \mathrm{~h}$ KA vs. roscovitine $+3 \mathrm{~h} \mathrm{KA}$ ). Immunolabeling of GluR6/7 in roscovitinetreated neurons revealed a localization of the receptor adjacent to the cell membrane, which was more pronounced in cells treated with KA (Fig. 5C). Apart from roscovitine, we modulated the level or activity of Cdk5 in hippocampal neurons using siRNA and DN constructs for Cdk5. Data showed that the DN-Cdk5 counteracted the decrease in PSD95 and GluR6 induced by KA in the neurons (Fig. 5D and E; one-way ANOvA with Bonferroni post-hoc test, $P<0.05$ for KA vs. DN-Cdk5+KA in the case of GluR6/7 and $P<0.01$ for KA vs. DN-Cdk5+KA in the case of PSD95). Similarly, the downregulation of $\mathrm{Cdk} 5$ using siRNA prevented the decrease in GluR6/7 caused by KA (Fig. 5F and G; one-way ANOvA with Bonferroni post-hoc test, $P<0.05$ for KA vs. DN-Cdk5+KA). As the inhibition of Cdk5 affected the levels of GluR6/7 we hypothesized that this might affect the calcium movements in the neurons. Thus, we used calcium imaging as described in Materials and methods to distinguish between DN-Cdk5-expressing or roscovitine-treated and control neurons. However, there was no significant difference in calcium movements between control and Cdk5-inhibited neurons (data not shown).

To study the long-term effects of Cdk5 inhibition, we analyzed the neuronal cell death induced by KA after $24 \mathrm{~h}$. Data showed that the number of degenerating neurons was reduced in cultures treated with DN-Cdk5 compared with KA-treated controls (Fig. 5H; one-way ANOVA with Bonferroni post-hoc test, $P<0.01$ for control vs. KA and $P<0.05$ for KA vs. DN-Cdk5+KA). This shows that the neuronal damage induced by $\mathrm{KA}$ is less in the presence of the DN-Cdk5 construct inhibiting Cdk5 activity.

\section{Discussion}

In this work, we show that treatment with an excitotoxic dose of KA causes a rapid degeneration of mossy fiber synapses and a decrease in GluR6/7 levels in rat hippocampus in vivo as well as in cultured hippocampal neurons. The results obtained support the view that Cdk5 deregulation is instrumental in this process, as it occurs subsequent to the cleavage of the activator protein $\mathrm{p} 35$ that is induced by calpain and by the elevation of intracellular calcium levels in hippocampal neurons after KA stimulation. In keeping with this, inhibition of Cdk5 using roscovitine or employing DN-Cdk5 and siRNA constructs counteracted the decreases in GluR6/7 and PSD95 observed after KA in cultured hippocampal neurons. The present results on the involvement of Cdk5 in KA-mediated excitotoxicity add to previous findings on the 


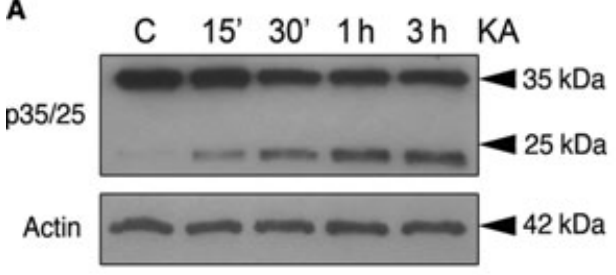

C

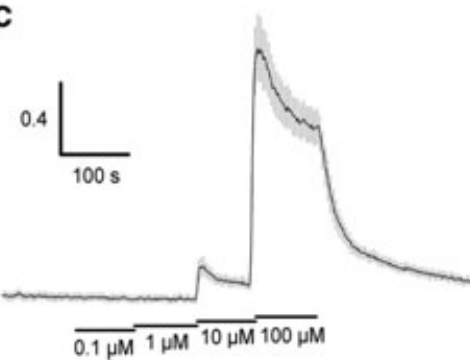

E

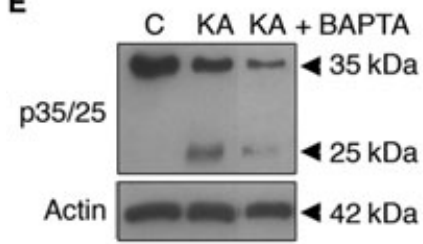

G

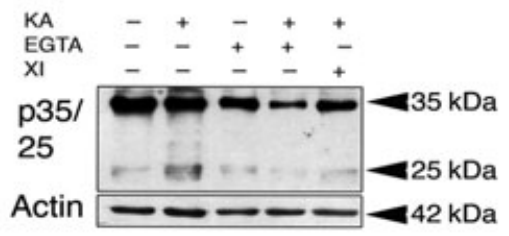



D
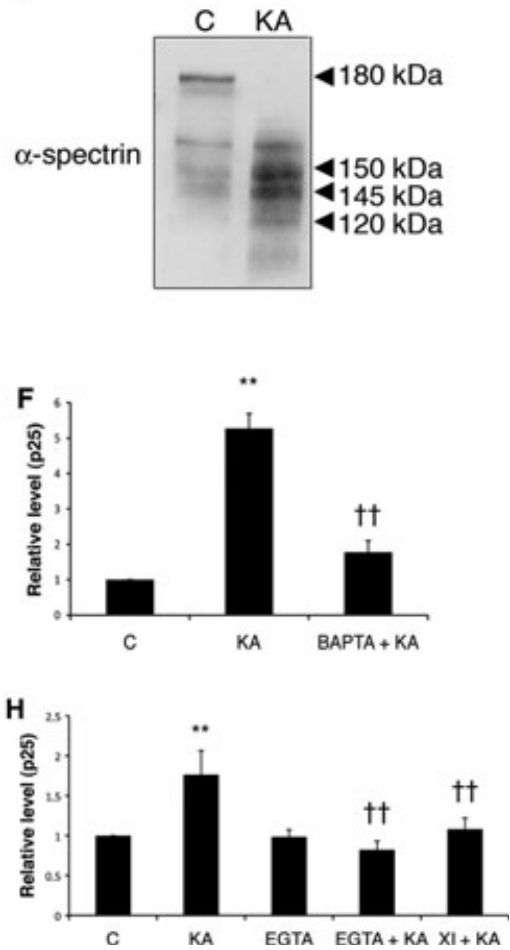

FIG. 3. KA induces a calcium- and calpain-dependent cleavage of the p35 protein in cultured hippocampal neurons. (A and B) Immunoblots. Hippocampal neurons were treated with $100 \mu \mathrm{M} \mathrm{KA}$ for different times. The Cdk5 activator p35 was cleaved into the p25 fragment after KA. $\beta$-actin was used as control (C). Values are means + SEM, $n=4$. ${ }^{*} P<0.01$ for KA treatment vs. C. (C) Fura-2 calcium imaging was performed as described in Materials and methods. Typical Ca ${ }^{2+}$ response to KA is shown as an average trace \pm SEM (a single experiment with 35 cells). For the sake of clarity, error bars are only drawn for every other point. Cells were stimulated with increasing concentrations of KA as indicated. The vertical calibration bar indicates the ratio $340: 380$. (D) Immunoblots. Activation of calpain produces a specific cleavage of $\alpha$-spectrin shown here as the $145 \mathrm{kDa}$ protein fragment. A typical experiment is shown and was repeated three times. (E and F) Immunoblots. Hippocampal neurons were treated with the calcium chelator (1 mM BAPTA-AM) at 30 min prior to KA. BAPTA-AM reduced the cleavage of p35 to the $\mathrm{p} 25$ protein. $\beta$-actin was used as control (C). Values are means $+\mathrm{SEM}, n=4 . * * P<0.01$ for KA vs. $\mathrm{C}$ and ${ }^{\dagger \dagger} P<0.01$ for KA+BAPTA-AM vs. KA. (G and H) The calcium chelator EGTA and the calpain inhibitor XI decreased the KA-induced increase in $\mathrm{p} 25 . \beta$-actin was used as control (C). Values are means + SEM, $n=4$. ${ }^{* *} P<0.01$ for KA vs. C. and ${ }^{\dagger \dagger} P<0.01$ for EGTA+KA and XI+KA vs. KA.

importance of Cdk5 in Alzheimer's disease (Kobayashi et al., 1993; Noble et al., 2003) and other neurological disorders (reviewed in Dhariwala \& Rajadhyaksha, 2008).

Cyclin-dependent kinase-5 has been implicated in numerous processes in the nervous system ranging from developmental effects in neurons to modulation of synaptic plasticity and learning in adults (Ohshima et al., 1996; Chae et al., 1997; Zhang et al., 1997; Hawasli \& Bibb, 2007; Lai \& Ip, 2009). Activation of Cdk5 requires the binding of the activator proteins, p35 or p39, which have a rather restricted expression in brain tissue (Tsai et al., 1994; Cai et al., 1997). At the subcellular level, Cdk5 localizes to the cytoplasm and nucleus (Ino \& Chiba, 1996). However, the interaction of Cdk5 with myristoylated $\mathrm{p} 35$ or $\mathrm{p} 39$ leads to the recruitment of $\mathrm{Cdk} 5$ to cellular membranes both in the cell soma and within dendrites (Asada et al., 2008). It has been shown that the cleavage of p35 into p25 affects Cdk5 in several ways, by influencing the activity, localization and protein-protein interactive network of Cdk5 (Kusakawa et al., 2000;
Lee et al., 2000; Patzke \& Tsai, 2002). Recently, inhibition of Cdk5 activity was shown to potentiate the release of neurotransmitters and thereby unmask so-called 'silent' synapses in neurons (Kim \& Ryan, 2010). In the post-synaptic compartment, Cdk5 regulates dendritic spine formation through phosphorylation of cytoskeleton-binding proteins, including neurofilaments and microtubule-associated proteins, as well as Tau and other signaling molecules (reviewed in Lai \& Ip, 2009). Activation of Cdk5 after increased neuronal activity was shown to phosphorylate the N-terminal domain of PSD95 and decrease the clustering of PSD95 and NMDA receptors at synapses, whereas the inhibition of Cdk5 had the opposite effects (Morabito et al., 2004). Cdk5 was further shown to phosphorylate the NMDA receptor subunit $2 \mathrm{~A}$ and to enhance NMDA-mediated currents in hippocampal neurons (Li et al., 2001). Studies of conditionally Cdk5 gene-deleted mice showed that the degradation of NMDA receptor subunit NMDA receptor subunit $2 \mathrm{~B}$ and the threshold for induction of long-term potentiation were altered in brain (Hawasli et al., 2007). 
A

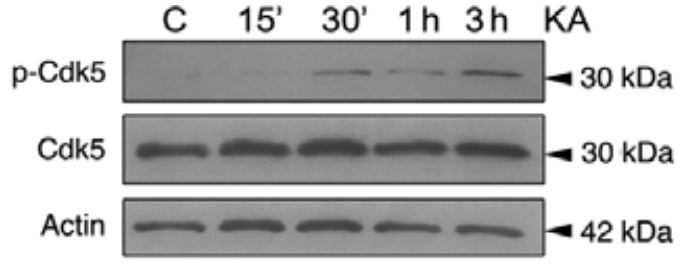

B

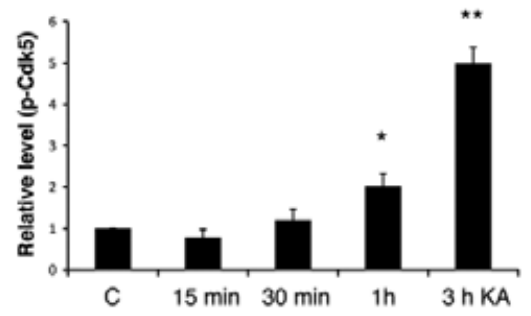

C

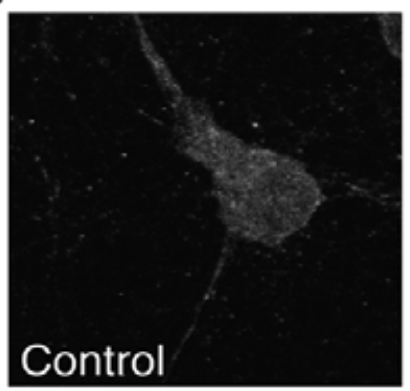

D

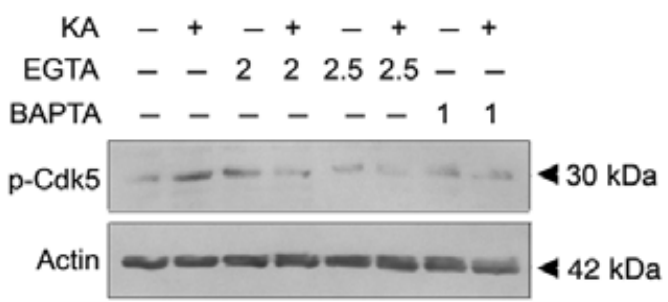

$\mathbf{E}$

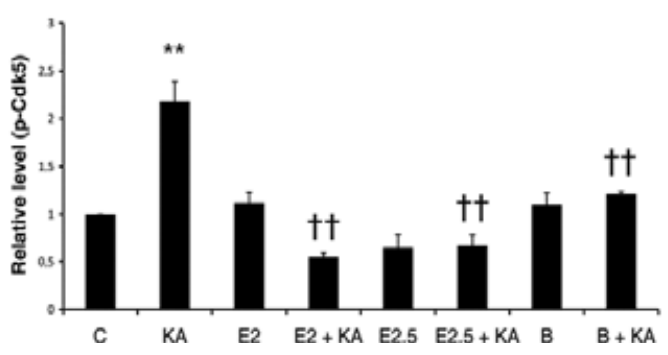

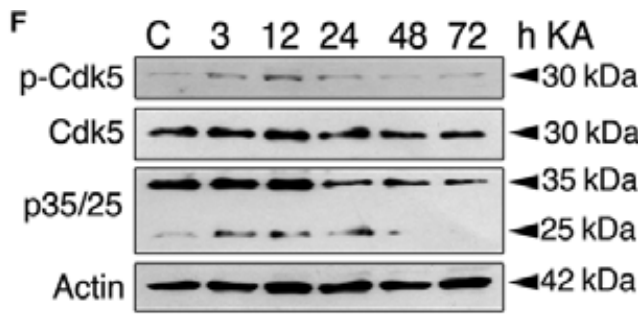

G
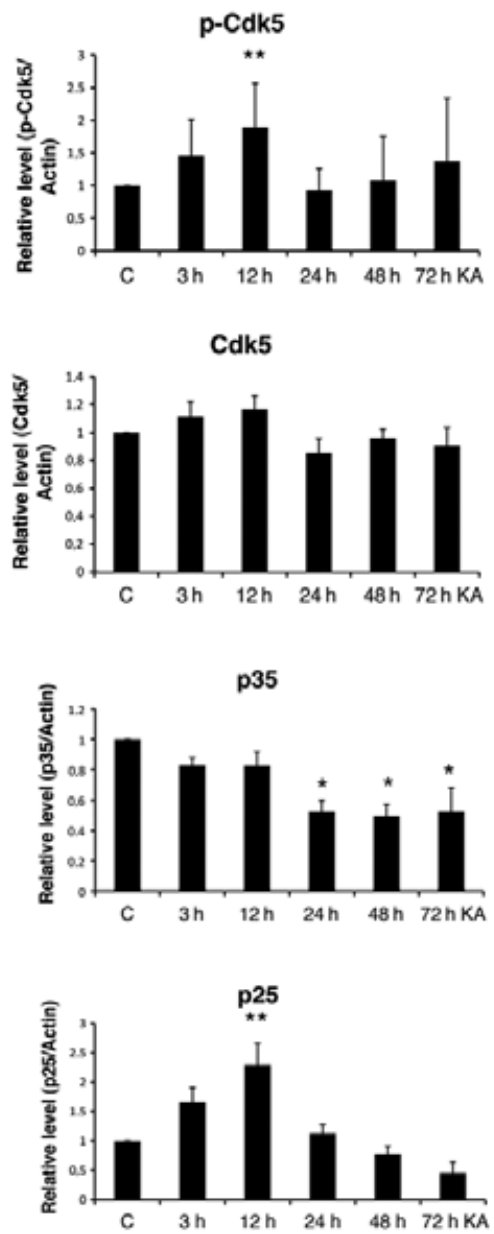

FIG. 4. KA treatment induces Cdk5 phosphorylation in hippocampal neurons in culture and in vivo. Hippocampal neurons were treated with $100 \mu \mathrm{M}$ KA for different times and analyzed further as indicated. Administration of KA in vivo was performed as in Fig. 1. (A and B) Immunoblots. Phosphorylation of Cdk5 (p-Cdk5) was induced by KA stimulation with no changes in total Cdk5 levels. Values are means + SEM, $n=4$. ** $P<0.01$ and $* P<0.05$ for KA vs. control (C). (C) Immunostaining of cultured neurons. Phosphorylated Cdk5 is localized particularly within neurites at 30 min after KA stimulation. Scale bar, $10 \mu \mathrm{m}$. (D and E) Immunoblots. Pre-treatment with $2 \mathrm{mM}$ EGTA (E2) or $2.5 \mathrm{~mm}$ EGTA (E2.5) or $1 \mathrm{~mm}$ BAPTA-AM (B) reduced the increase in p-Cdk5 induced by KA. Values are means + SEM, $n=4 . * * P<0.01$ for KA vs. $\mathrm{C}$ and ${ }^{\dagger \dagger} P<0.01$ for EGTA+KA and BAPTA-AM+KA treatments vs. KA. (F) In vivo experiments. KA was administrated for $12 \mathrm{~h}$. Note the increase in the levels of p25 and p-Cdk5 in the hippocampus by KA. $\beta$-actin was used as control (C). (G) Values are means + SEM, $n=4$. $* * P<0.01$ for $12 \mathrm{~h} \mathrm{KA}$ vs. C in the case of $\mathrm{p}-\mathrm{Cdk} 5$ and $\mathrm{p} 25$, and $* P<0.05$ for $24 \mathrm{~h}$ KA vs. C in the case of $\mathrm{p} 35$.

Recently, Cdk5 was also shown to regulate the $\alpha$-amino-3-hydroxy-5methylisoxazole-4-propionic acid receptor subunit GluR2-mediated synaptic activity via phosphorylation of D-catenin (Poore et al., 2010).

In this work, we have studied the involvement of Cdk5 in KA-induced excitotoxicity in neurons, and particularly analyzed the synaptic proteins, GluR6/7 and PSD95, that are important for proper glutamatergic neurotransmission in the mossy fibers in the hippocampus. We show here that KA stimulation induced a phosphorylation of $\mathrm{Cdk} 5$ and an increased cleavage of the regulatory protein $\mathrm{p} 35$ in cultured hippocampal neurons. Similar changes were also observed in hippocampus in vivo with the largest effects observed at $12 \mathrm{~h}$ after KA administration. As studied in vitro, the cleavage of $\mathrm{p} 35$ and the increase in $\mathrm{p}-\mathrm{Cdk} 5$ depended on the increase in intracellular 
A

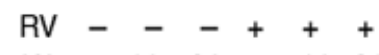

$\mathrm{KA}-1 \mathrm{~h} 3 \mathrm{~h}-1 \mathrm{~h} 3 \mathrm{~h}$

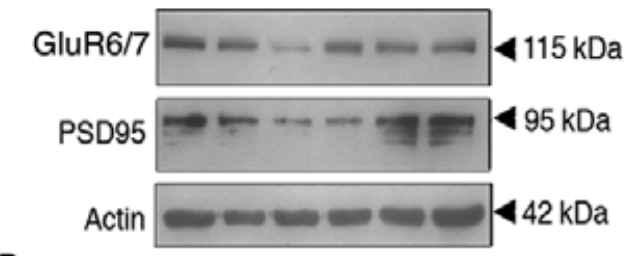

B

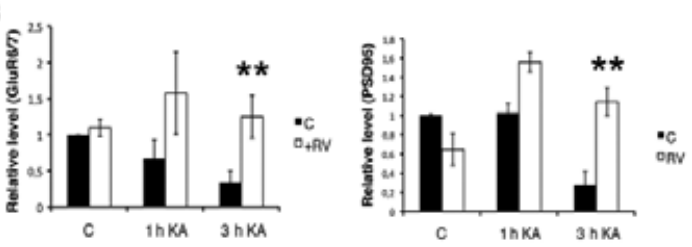

C
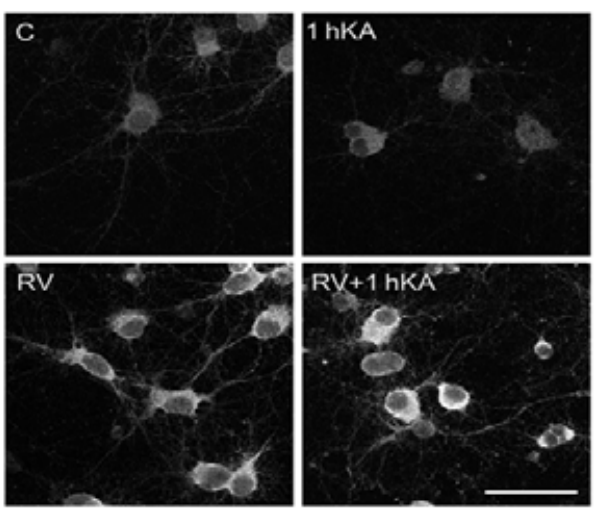

D $\underset{\mathrm{KA}}{\mathrm{DN}-\mathrm{Cdk} 5}-\overline{+}+$

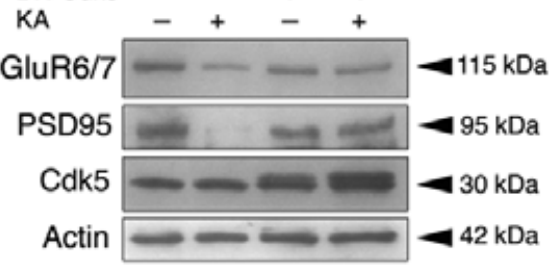

E

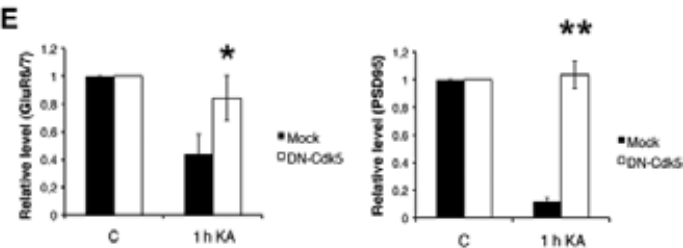

F

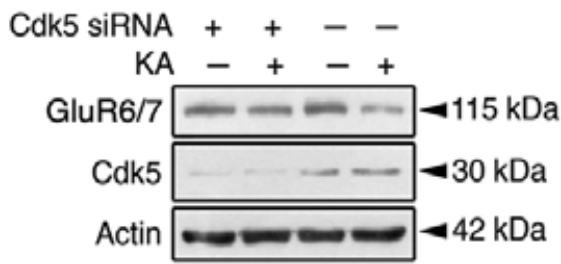

G

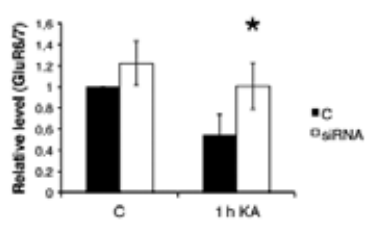

H

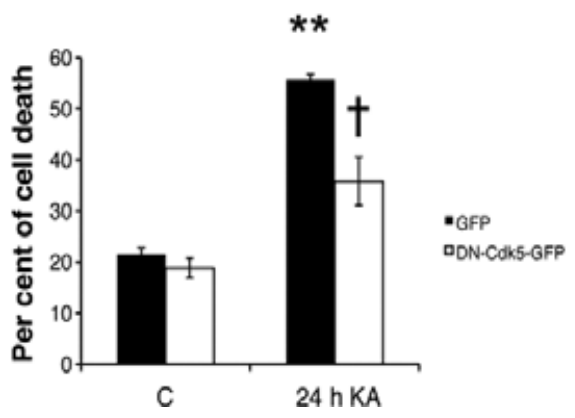

FIG. 5. Inhibition of Cdk5 counteracts KA-induced downregulation of PSD95 and GluR6 in cultured hippocampal neurons. Hippocampal neurons were treated with $100 \mu \mathrm{M} \mathrm{KA}$ alone or in the presence of the cyclin-dependent kinase inhibitor roscovitine (RV). In some experiments, neurons were transfected with siRNA against Cdk5 or with the dominant-negative (DN) Cdk5 construct prior to KA treatments. (A and B) Immunoblots. Addition of RV counteracts the downregulation of GluR6/7 and PSD95 induced by KA. Values are means $\pm \mathrm{SEM}, n=3$. **P $<0.01$ for RV+KA vs. KA at $3 \mathrm{~h}$. (C) Confocal images of hippocampal neurons were acquired as described in Materials and methods. Note the increased GluR6/7 immunostaining by roscovitine in KA-treated neurons. Scale bar, $50 \mu \mathrm{m}$. (D and E) Immunoblots. Expression of DN-Cdk5-hemagglutinin reduced the decrease in GluR6/7 and PSD95 induced by KA at $3 \mathrm{~h}$. Values are means \pm SEM, $n=3$. $* P<0.05$ or $* * P<0.01$ for DN-Cdk5+KA vs. KA in the case of both GluR6/7 and PSD95. (F and G) Immunoblots. Cdk5-siRNA reduced Cdk5 levels in neurons at 5 days of transfection and reduced the decrease in GluR6/7 induced by KA. Values are means \pm SEM, $n=3 . * P<0.05$ for siRNA+KA vs. KA. (H) Neurons transfected with DN-Cdk5-EGFP or with EGFP as controls (C) were stimulated with $100 \mu \mathrm{M}$ KA for $24 \mathrm{~h}$. Nuclei were labeled with Hoechst blue and the number of transfected cells with condensed or fragmented chromatin was counted as an index of degenerating cells. Values are means \pm SEM, $n=3$. $* * P<0.01$ for KA vs. $\mathrm{C}$ and ${ }^{\dagger} P<0.05$ for DN-Cdk5+KA vs. KA.

calcium brought about by KA as this was blocked by BAPTA-AM and EGTA. Inhibition of the calcium-dependent protease calpain also reduced the p35 cleavage induced by KA. This indicates that KA can activate calpain at an early stage, which links the calcium increase to subsequent downstream cellular events in excitotoxicity. Our study with KA confirms previous data showing a cleavage of p35 after activation of GluRs using NMDA, $\alpha$-amino-3-hydroxy-5- methylisoxazole-4-propionic acid and glutamic acid as agonists (Kerokoski et al., 2004). However, the links between p35 and the deregulation of $\mathrm{Cdk} 5$ and alterations in synaptic proteins and neuronal excitotoxicity induced by KA have not been documented before.

It has been shown that KARs participate in the excitatory postsynaptic currents occurring between the mossy fibers and CA3 
pyramidal cells (Castillo et al., 1997). In the pre-synaptic compartment, KARs affect the neurotransmitter release through activation of GluR6/GluR7 (Lerma, 2006). In addition, extrasynaptic KARs, in CA1 pyramidal cells, may increase neuronal excitability through a metabotropic action (Melyan et al., 2002). In GluR6 gene-deleted mice, the mossy fiber excitatory post-synaptic currents and the presynaptic actions of KARs are missing (Mulle et al., 1998; Contractor et al., 2001). Recently, KARs were shown to control the efficacy of spike transmission between pre-synaptic granule cells and CA3 pyramidal cells by a combination of pre- and post-synaptic actions (Sachidhanandam et al., 2009). Polymorphisms in the GluR6 gene have been associated with a number of mental disorders, e.g. schizophrenia and bipolar disorders (Beneyto et al., 2007; Blackwood et al., 2007). As shown in GluR6 gene-deleted mice, activation of GluR6 is central for epileptiform seizures induced by KA and for cell death in the hippocampal CA3 area (Mulle et al., 1998).

In this work, we have identified Cdk5 as an important downstream target for the action of KA in hippocampal neurons. Blocking of the Cdk5 pathway by roscovitine or using the DN-Cdk 5 construct restored the levels of GluR6/7 and PSD95 in hippocampal neurons stimulated by KA. Roscovitine is an inhibitor of the cyclin-dependent kinase family of proteins including $\mathrm{Cdk} 5$, and it has been shown to be neuroprotective in animal models for focal ischemia and in different tauopathies (Wen et al., 2007; Menn et al., 2010). The structurally related compound olomoucine also reduces ischemia-induced reactive astrogliosis (Zhu et al., 2007). However, both roscovitine and olomoucine may also have unwanted effects that may preclude their direct application in neurological disorders. It was recently reported that the $\mathrm{Cdk} 5 / \mathrm{p} 25$ inhibitory peptide, which targets only the deregulated $\mathrm{Cdk} 5 / \mathrm{p} 25$ complex (Zheng et al., 2002), showed promising effects in nerve cell cultures (Kanungo et al., 2009). However, more studies on this peptide are needed to elucidate its effects in vivo as a potentially beneficial agent in neurodegeneration (Kanungo et al., 2009).

Taken together, the present findings show an essential function of Cdk5 in the regulation of synaptic integrity and GluR6/7 and PSD5 levels in excitotoxicity induced by KA in hippocampal neurons. Cdk5 has different protein target proteins and affects various signaling events in neurons. The mechanisms through which Cdk5 influences synaptic proteins and excitotoxicity in neurons remain to be studied further.

\section{Acknowledgements}

We thank E. Lehto and J. Mäkelä for excellent technical assistance, and Dr van den Heuvel and Dr Tsai for DN-Cdk5 constructs. This work was supported by the Academy of Finland, Sigrid Juselius, Liv och Hälsa, Arvo and Lea Ylppö and Magnus Ehrnrooth Foundations, University of Helsinki Research Funds, Finska Läkaresällskapet, Minerva Foundation and Progetti di Ateneo, University of Palermo. N.P. was supported by the Helsinki Biomedical Graduate School, and J.P. by the Drug Discovery Graduate School. Confocal imaging was performed at Biomedicum Imaging Unit at Biomedicum-Helsinki.

\section{Abbreviations}

BAPTA-AM, 1,2-bis( $o$-aminophenoxy)ethane- $N, N, N^{\prime}, N^{\prime}$-tetra-acetic acid acetoxymethyl ester; CA, cornu ammonis; Cdk5, cyclin-dependent kinase-5; DN, dominant-negative; EGFP, enhanced green fluorescent protein; EGTA, glycolbis(2-aminoethylether)- $N, N, N^{\prime}, N^{\prime}$-tetra-acetic acid; GluR, glutamate receptor; GRIK, glutamate receptor ionotropic kainate; KA, kainic acid; KAR, kainate receptor; NMDA, $N$-methyl-D-aspartate; p-Cdk5, phospho-cyclin-dependentkinase-5; PSD95, post-synaptic density protein 95; siRNA, silencing RNA.

\section{References}

Asada, A., Yamamoto, N., Gohda, M., Saito, T., Hayashi, N. \& Hisanaga, S. (2008) Myristoylation of p39 and p35 is a determinant of cytoplasmic or nuclear localization of active cyclin-dependent kinase 5 complexes. $J$. Neurochem., 106, 1325-1336.

Beneyto, M., Kristiansen, L.V., Oni-Orisan, A., McCullumsmith, R.E. \& Meador-Woodruff, J.H. (2007) Abnormal glutamate receptor expression in the medial temporal lobe in schizophrenia and mood disorders. Neuropsychopharmacology, 32, 1888-1902.

Blackwood, D.H., Pickard, B.J., Thomson, P.A., Evans, K.L., Porteous, D.J. \& Muir, W.J. (2007) Are some genetic risk factors common to schizophrenia, bipolar disorder and depression? Evidence from DISC1, GRIK4 and NRG1 Neurotox. Res., 11, 73-83.

Bureau, I., Bischoff, S., Heinemann, S.F. \& Mulle, C. (1999) Kainate receptormediated responses in the CA1 field of wild-type and GluR6-deficient mice. J. Neurosci., 19, 653-663.

Cai, X.H., Tomizawa, K., Tang, D., Lu, Y.F., Moriwaki, A., Tokuda, M., Nagahata, S., Hatase, O. \& Matsui, H. (1997) Changes in the expression of novel Cdk5 activator messenger RNA (p39nck5ai mRNA) during rat brain development. Neurosci. Res., 28, 355-360.

Castillo, P.E., Malenka, R.C. \& Nicoll, R.A. (1997) Kainate receptors mediate a slow postsynaptic current in hippocampal CA3 neurons. Nature, $\mathbf{3 8 8}, 182$ 186.

Chae, T., Kwon, Y.T., Bronson, R., Dikkes, P., Li, E. \& Tsai, L.H. (1997) Mice lacking p35, a neuronal specific activator of Cdk5, display cortical lamination defects, seizures, and adult lethality. Neuron, 18, 29-42.

Chidlow, G., Wood, J.P., Sarvestani, G., Manavis, J. \& Casson, R.J. (2009) Evaluation of Fluoro-Jade $\mathrm{C}$ as a marker of degenerating neurons in the rat retina and optic nerve. Exp. Eye Res., 88, 426-437.

Contractor, A., Swanson, G. \& Heinemann, S.F. (2001) Kainate receptors are involved in short- and long-term plasticity at mossy fiber synapses in the hippocampus. Neuron, 29, 209-216.

Dhariwala, F.A. \& Rajadhyaksha, M.S. (2008) An unusual member of the cdk family: Cdk5. Cell. Mol. Neurobiol., 28, 351-369.

El-Khodor, B.F. \& Burke, R.E. (2002) Medial forebrain bundle axotomy during development induces apoptosis in dopamine neurons of the substantia nigra and activation of caspases in their degenerating axons. J. Comp. Neurol., 452, 65-79.

Hawasli, A.H. \& Bibb, J.A. (2007) Alternative roles for Cdk5 in learning and synaptic plasticity. Biotechnol. J., 2, 941-948.

Hawasli, A.H., Benavides, D.R., Nguyen, C., Kansy, J.W., Hayashi, K., Chambon, P., Greengard, P., Powell, C.M., Cooper, D.C. \& Bibb, J.A. (2007) Cyclin-dependent kinase 5 governs learning and synaptic plasticity via control of NMDAR degradation. Nat. Neurosci., 10, 880-886.

van den Heuvel, S. \& Harlow, E. (1993) Distinct roles for cyclin-dependent kinases in cell cycle control. Science, 262, 2050-2054.

Ino, H. \& Chiba, T. (1996) Intracellular localization of cyclin-dependent kinase 5 (CDK5) in mouse neuron: CDK5 is located in both nucleus and cytoplasm. Brain Res., 732, 179-185.

Jane, D.E., Lodge, D. \& Collingridge, G.L. (2009) Kainate receptors: pharmacology, function and therapeutic potential. Neuropharmacology, 56, 90-113.

Jaskolski, F., Coussen, F. \& Mulle, C. (2005) Subcellular localization and trafficking of kainate receptors. Trends Pharmacol. Sci., 26, 20-26.

Kairisalo, M., Korhonen, L., Sepp, M., Pruunsild, P., Kukkonen, J.P., Kivinen, J., Timmusk, T., Blomgren, K. \& Lindholm, D. (2009) NF-kappaBdependent regulation of brain-derived neurotrophic factor in hippocampal neurons by X-linked inhibitor of apoptosis protein. Eur. J. Neurosci., 30, 958-966.

Kanungo, J., Zheng, Y.L., Amin, N.D. \& Pant, H.C. (2009) Targeting Cdk5 activity in neuronal degeneration and regeneration. Cell. Mol. Neurobiol., 29, 1073-1080.

Kerokoski, P., Suuronen, T., Salminen, A., Soininen, H. \& Pirttila, T. (2004) Both $N$-methyl-D-aspartate (NMDA) and non-NMDA receptors mediate glutamate-induced cleavage of the cyclin-dependent kinase 5 (cdk5) activator p35 in cultured rat hippocampal neurons. Neurosci. Lett., 368, $181-185$.

Kim, S.H. \& Ryan, T.A. (2010) CDK5 serves as a major control point in neurotransmitter release. Neuron, 67, 797-809.

Kobayashi, S., Ishiguro, K., Omori, A., Takamatsu, M., Arioka, M., Imahori, K. \& Uchida, T. (1993) A cdc2-related kinase PSSALRE/cdk5 is homologous with the $30 \mathrm{kDa}$ subunit of tau protein kinase II, a prolinedirected protein kinase associated with microtubule. FEBS Lett., 335, 171175. 
Korhonen, L. \& Lindholm, D. (2004) The ubiquitin proteasome system in synaptic and axonal degeneration: a new twist to an old cycle. J. Cell Biol., 165, 27-30.

Korhonen, L., Belluardo, N. \& Lindholm, D. (2001) Regulation of $\mathrm{X}$-chromosome-linked inhibitor of apoptosis protein in kainic acid-induced neuronal death in the rat hippocampus. Mol. Cell. Neurosci., 17, 364-372.

Korhonen, L., Hansson, I., Kukkonen, J.P., Brannvall, K., Kobayashi, M., Takamatsu, K. \& Lindholm, D. (2005) Hippocalcin protects against caspase12-induced and age-dependent neuronal degeneration. Mol. Cell. Neurosci., 28, 85-95.

Kusakawa, G., Saito, T., Onuki, R., Ishiguro, K., Kishimoto, T. \& Hisanaga, S. (2000) Calpain-dependent proteolytic cleavage of the p35 cyclin-dependent kinase 5 activator to p25. J. Biol. Chem., 275, 17166-17172.

Lai, K.O. \& Ip, N.Y. (2009) Recent advances in understanding the roles of Cdk5 in synaptic plasticity. Biochim. Biophys. Acta, 1792, 741-745.

Lee, M.S., Kwon, Y.T., Li, M., Peng, J., Friedlander, R.M. \& Tsai, L.H. (2000) Neurotoxicity induces cleavage of p35 to p 25 by calpain. Nature, $\mathbf{4 0 5}, 360$ 364.

Lerma, J. (2006) Kainate receptor physiology. Curr. Opin. Pharmacol., 6, 8997.

Li, B.S., Sun, M.K., Zhang, L., Takahashi, S., Ma, W., Vinade, L., Kulkarni, A.B., Brady, R.O. \& Pant, H.C. (2001) Regulation of NMDA receptors by cyclin-dependent kinase-5. Proc. Natl. Acad. Sci. USA, 98, $12742-12747$.

Mattson, M.P. (2003) Excitotoxic and excitoprotective mechanisms: abundant targets for the prevention and treatment of neurodegenerative disorders. Neuromolecular Med., 3, 65-94.

Meijer, L., Borgne, A., Mulner, O., Chong, J.P., Blow, J.J., Inagaki, N., Inagaki, M., Delcros, J.G. \& Moulinoux, J.P. (1997) Biochemical and cellular effects of roscovitine, a potent and selective inhibitor of the cyclindependent kinases cdc2, cdk2 and cdk5. Eur. J. Biochem., 243, 527-536.

Melyan, Z., Wheal, H.V. \& Lancaster, B. (2002) Metabotropic-mediated kainate receptor regulation of IsAHP and excitability in pyramidal cells. Neuron, 34, 107-114.

Menn, B., Bach, S., Blevins, T.L., Campbell, M., Meijer, L. \& Timsit, S. (2010) Delayed treatment with systemic (S)-roscovitine provides neuroprotection and inhibits in vivo CDK5 activity increase in animal stroke models. PLoS One, 5, e12117.

Morabito, M.A., Sheng, M. \& Tsai, L.H. (2004) Cyclin-dependent kinase 5 phosphorylates the N-terminal domain of the postsynaptic density protein PSD-95 in neurons. J. Neurosci., 24, 865-876.

Mulle, C., Sailer, A., Perez-Otano, I., Dickinson-Anson, H., Castillo, P.E., Bureau, I., Maron, C., Gage, F.H., Mann, J.R., Bettler, B. \& Heinemann, S.F. (1998) Altered synaptic physiology and reduced susceptibility to kainate-induced seizures in GluR6-deficient mice. Nature, 392, 601-605.

Nakamura, S., Kawamoto, Y., Nakano, S., Akiguchi, I. \& Kimura, J. (1997) p35nck5a and cyclin-dependent kinase 5 colocalize in lewy bodies of brains with Parkinson's disease. Acta Neuropathol., 94, 153-157.

Noble, W., Olm, V., Takata, K., Casey, E., Mary, O., Meyerson, J., Gaynor, K., LaFrancois, J., Wang, L., Kondo, T., Davies, P., Burns, M., Veeranna, A., Nixon, R., Dickson, D., Matsuoka, Y., Ahlijanian, M., Lau, L.F. \& Duff, K. (2003) Cdk5 is a key factor in tau aggregation and tangle formation in vivo. Neuron, 38, 555-565.

Ohshima, T., Ward, J.M., Huh, C.G., Longenecker, G., Veeranna, A., Pant, H.C., Brady, R.O., Martin, L.J. \& Kulkarni, A.B. (1996) Targeted disruption of the cyclin-dependent kinase 5 gene results in abnormal corticogenesis, neuronal pathology and perinatal death. Proc. Natl. Acad. Sci. USA, 93 $11173-11178$

Orlando, L.R., Ayala, R., Kett, L.R., Curley, A.A., Duffner, J., Bragg, D.C. Tsai, L.H., Dunah, A.W. \& Young, A.B. (2009) Phosphorylation of the homer-binding domain of group I metabotropic glutamate receptors by cyclin-dependent kinase 5. J. Neurochem., 110, 557-569.

Paoletti, P., Vila, I., Rife, M., Lizcano, J.M., Alberch, J. \& Gines, S. (2008) Dopaminergic and glutamatergic signaling crosstalk in Huntington's disease neurodegeneration: the role of p25/cyclin-dependent kinase 5. J. Neurosci., 28, 10090-10101.

Patzke, H. \& Tsai, L.H. (2002) Calpain-mediated cleavage of the cyclindependent kinase-5 activator p39 to p29. J. Biol. Chem., 277, 8054-8060.

Poore, C.P., Sundaram, J.R., Pareek, T.K., Fu, A., Amin, N., Mohamed, N.E., Zheng, Y.L., Goh, A.X., Lai, M.K., Ip, N.Y., Pant, H.C. \& Kesavapany, S. (2010) Cdk5-mediated phosphorylation of delta-catenin regulates its localization and GluR2-mediated synaptic activity. J. Neurosci., 30, 8457-8467.

Reijonen, S., Putkonen, N., Norremolle, A., Lindholm, D. \& Korhonen, L. (2008) Inhibition of endoplasmic reticulum stress counteracts neuronal cell death and protein aggregation caused by N-terminal mutant huntingtin proteins. Exp. Cell Res., 314, 950-960.

Reijonen, S., Kukkonen, J.P., Hyrskyluoto, A., Kivinen, J., Kairisalo, M., Takei, N., Lindholm, D. \& Korhonen, L. (2010) Downregulation of NFkappaB signaling by mutant huntingtin proteins induces oxidative stress and cell death. Cell. Mol. Life Sci., 67, 1929-1941.

Sachidhanandam, S., Blanchet, C., Jeantet, Y., Cho, Y.H. \& Mulle, C. (2009) Kainate receptors act as conditional amplifiers of spike transmission at hippocampal mossy fiber synapses. J. Neurosci., 29, 5000-5008.

Sokka, A.L., Putkonen, N., Mudo, G., Pryazhnikov, E., Reijonen, S., Khiroug, L., Belluardo, N., Lindholm, D. \& Korhonen, L. (2007) Endoplasmic reticulum stress inhibition protects against excitotoxic neuronal injury in the rat brain. J. Neurosci., 27, 901-908.

Tsai, L.H., Delalle, I., Caviness, V.S. Jr, Chae, T. \& Harlow, E. (1994) P35 is a neural-specific regulatory subunit of cyclin-dependent kinase 5. Nature, 371, $419-423$.

Vanderklish, P.W. \& Bahr, B.A. (2000) The pathogenic activation of calpain: a marker and mediator of cellular toxicity and disease states. Int. J. Exp. Pathol., 81, 323-339.

Vincent, P. \& Mulle, C. (2009) Kainate receptors in epilepsy and excitotoxicity. Neuroscience, 158, 309-323.

Weishaupt, J.H., Neusch, C. \& Bahr, M. (2003) Cyclin-dependent kinase 5 (CDK5) and neuronal cell death. Cell Tissue Res., 312, 1-8.

Wen, Y., Yang, S.H., Liu, R., Perez, E.J., Brun-Zinkernagel, A.M., Koulen, P. \& Simpkins, J.W. (2007) Cdk5 is involved in NFT-like tauopathy induced by transient cerebral ischemia in female rats. Biochim. Biophys. Acta, $\mathbf{1 7 7 2}$ 473-483.

Zhang, Q., Ahuja, H.S., Zakeri, Z.F. \& Wolgemuth, D.J. (1997) Cyclindependent kinase 5 is associated with apoptotic cell death during development and tissue remodeling. Dev. Biol., 183, 222-233.

Zheng, Y.L., Li, B.S., Amin, N.D., Albers, W. \& Pant, H.C. (2002) A peptide derived from cyclin-dependent kinase activator (p35) specifically inhibits Cdk5 activity and phosphorylation of tau protein in transfected cells. Eur. $J$. Biochem., 269, 4427-4434.

Zhu, Z., Zhang, Q., Yu, Z., Zhang, L., Tian, D., Zhu, S., Bu, B., Xie, M. \& Wang, W. (2007) Inhibiting cell cycle progression reduces reactive astrogliosis initiated by scratch injury in vitro and by cerebral ischemia in vivo. Glia, 55, 546-558. 